Journal of Education and Vocational Research

Vol. 5, No. 4, pp. 165-174, December 2014 (ISSN 2221-2590)

\title{
Sources of Information Referred for Higher Education Institution Selection
}

\author{
Noor Ismawati Mohd Jaafar \\ University of Malaya, Kuala Lumpur, Malaysia \\ nimj@um.edu.my
}

\begin{abstract}
In response to the increase in demand on tertiary education, number of higher education institution raised dramatically over the past few decades. The scenario creates competition environment leading to the needs for understanding how students' decision were made. Recent literature on higher education has been acknowledging the role of marketing in attracting potential students. This paper explores the decision process of selecting higher education institution within the framework of marketing communication. From the perception of students who are successfully accepted in a higher education institution, the analysis was done to investigate what was the source of information being referred. Analysis was also done to identify which source perceived by the students as their most influential source of information in deciding which institution to apply for. The finding suggests that traditional marketing tools such as news paper and magazine advertisement or publication is still effective as compared with other interactive marketing approach such as websites and education fair. The influence of their significant others such as parents, siblings and peers is also discussed.
\end{abstract}

Keywords: Marketing Communication, Higher Education, Student Choice, Undergraduate, Perception

\section{Introduction}

Due to various factors, the demand for tertiary education is growing rapidly in most parts of the world. As the number of higher education institution (HEI) increases and competition is no longer bounded by geographical factor, private and public institutions are putting more efforts on attracting potential students by incorporating marketing theories and concepts in their marketing strategy. Unlike other service based industry, higher education marketization needs to be done cautiously to ensure the HEI is not deviated from its core function to exchange knowledge, provide academic training and skills transfer. As noted by HemsleyBrown \& Oplatka (2006), researches done on higher education marketing and consumer behavior are substantial. However, they believes that there are more works to be done and described the current literature addressing the area as incoherent, even inchoate, and lacks theoretical models that reflect upon the particular context of higher education and the nature of their services. In order to understand student decision making in selecting HEI were made; the source of information being referred is one of the topics of interest. For the supply side, the HEI uses various marketing communication tools in sending the message to their target market for enrollment. From the other side of the communication channel, these messages are treated as information. To them, the marketing communication tools used are the source of information. Based on marketing communication framework adopted by Hughes and Fill (2007), the paper discussed about source of information being referred in selecting HEI. Dealing with various types of stakeholders, HEI studies on enrollment for undergraduate and postgraduate level should be done separately. As they refer to different age cohort with distinctly different nature of product or services, they should be treated as different market segment. Focusing on the undergraduate studies, the paper explores the students' behavior in helping HEI to select the most effective integrated marketing communication tools mix. Based on a survey conducted among first year students, the paper seeks answer on which source did they referred to in the process of selecting HEI for their undergraduate studies, did they refers to multiple sources and which source was considered as the most important ones? Ultimately the best combination of marketing communication tools would be recommended for the specified target group. 


\section{HEI Marketing Communication}

The basic marketing communication or originally known as promotion is used to communicate elements of an organization's products, services or the organization's itself to a target audience for building its reputation (Fill, 2009). Promotion is one out of four main concepts in 4P's marketing mix. The elements is not limited to the product or services in transaction but also covers other aspect of the before and after sales and/or services including market awareness. The simplest communication process model involves the source of the message, the message itself and the receiver of the message. More comprehensive models; for example Barnlund (2008), Berlo (1960), Shannon and Weaver (1949), Schramm (1954) and Wood (2009); acknowledge the existence of other factors that could distract or enhance the message delivery and receiving process. This section is reviews the theory and concept in marketing communication applicable for HEI especially on the tools and its application.

Source of Message: From relationship marketing perspective, there are five possible sources of messages which are categorized into five groups, namely, planned, product, service, unplanned messages and absence of communication (Duncan \& Moriarty, 1997; Colonius, 1989 as summarized in Gönroos, 2004). The planned message is used for marketing communication process done through communication media and other communication efforts. While planned message includes television commercials, brochure, banners, direct response, sales and website; the unplanned messages includes word-of-mouth, referrals, references, news stories, gossips, and online chat groups, which is also known as marketing communicating tools, product and services messages are not only subjected to the physical appearance of the product or services offered. The product message is about the usefulness of the product or services, design, technical features, appearance, raw materials and production process. Interaction with service process, deliveries, invoicing, claim handling, product documentation and help centre are examples of service messages. As discussed by Colonius (1989) the absence of communication also sends distinct messages. From the perspective of the receiver of the message, the message received is considered as information. Perhaps this is why the term source of information was used in most literature on HEI marketing especially when the study is done from the point of view of the potential applicant or students which is the receiver. Since the analysis was done based the students perception, the paper uses the term information instead of message.

Marketing Communication tools: In information delivery process, the medium used as marketing communication tools has becoming more sophisticated from paid advertisement on printed material such as broachers, newspapers, magazines to electronic formats such as television and radio and more up-to-date online medium. Advertisement, sales promotion, personal selling, direct marketing and public relation are the four main tools in marketing communication (Fill, 2009; Kotler et al., 1996). In response to changes in market and environmental conditions, sponsorship is a new and innovative form of communication which is categorized as value-added approaches by Fill and Jamieson (2006). Advertising offers reason to buy with non-personal communication between seller and its target audience. The information must be send through a paid media such as on commercials aired on television or radio, printed advertisement on magazine or newspaper, posters displayed on billboard and banners (Kotler et al., 2006). The banners could be hanged on the wall or attached to website with hyperlinks. Sale promotion consists of short-term incentives to increase the desire of the target group and encourage them for instant purchase (Kazmi and Batra, 2008). For targeting the final buyer, it can be done by organizing contest, distributing coupons, free sample, freebies and offering rebates, vouchers and discounts. Financial deals such as zero percent financing and merchandising also falls under sale promotion. Personal selling is defined as oral presentation in a conversation with one or more prospective purchasers of making sales and building customer relationships (Kotler et al., 2006).

As discussed by Cant and van Heerden (2005), even though personal selling is flexible, builds relationship and allows for more efficient communication as it's a form of dynamic communication; it can be expensive and may involve unethical practices. Direct marketing is the one-on-one communications between marketer and prospect/customer not restricted to any medium to stimulate an immediate behavior modification in such a way that this behavior can be tracked, recorded, analyzed and stored on a database for future retrieval and use (Stone and Jacob, 2007). Direct mail, telemarketing, electronic marketing, online marketing are examples of direct marketing (Kotler et al., 2006). According to Chartered Institute of Public Relations, public relation is about reputation - the result of what you do, what you say and what others say about you. Public Relations 
Practice is the discipline which looks after reputation with the aim of earning understanding and support, and influencing opinion and behavior. Typical activities include press releases, press kits, newsletters and public appearances. Sponsorship is a kind of partnership where both parties can get benefits from the exchanging funds and the use of certain rights (Masterman, 2007). With well-directed sponsorship, the image and perceptions toward the company and its product can be enhanced or otherwise have no effect at all or at worst, backfire (McDonald, 1991). Each tool is suitable for various purposes. Advertisement and sponsorship is very useful to create awareness; sales promotion for motivation; personal selling and direct marketing for more personal approach and public relation for branding.

For HEI, the most common tools used are print media; direct mail; outdoor posters, banners and billboards; online advertisements; and email advertising to make known their institutions and the programmes they offer (Jansen and Brenn-White, 2011 as summarized in Atarah and Peprah, 2014). Advertisement was found to be one of the sources of information for students who goes to private HEI and influencing their enrollment decision (Atarah and Peprah, 2014). It was shown to be the most effective marketing communication tools (Bamfo and Atara, 2013; Messah and Immaculate, 2011). A research among Chinese high school and junior colleges students in Singapore and Malaysia by Chung (2010) discovered that traditional print media such as magazines, newspapers, and brochures, television and word of mouth (testimonials, alumni) are not the most effective advertising channels to potential tertiary student from Singapore and Malaysia. Instead, agents, trade/education fairs, open day, sponsorship and the Web were more preferable as source of information. In contrast, Gray et al. (2003) emphasis on the significant of print media and television. Messah and Immaculate (2011) concludes that there is significant relationship between advertising, personal selling, direct marketing and public relations activities with student enrolment. They identified newspapers, brochures and alumni networks as more effective as compared with billboards, posters, radio, university newsletters, and alumni magazines. They also stressed the important of declaring how HEI product and services were ranked against some benchmarks or ratings as part of public relation strategy. HEI should also organizing university visits, education fair or exhibition and career day for potential customer. At the same time HEI should approach its target market though school visits and use their alumni networks. The findings from previous research discussed here were done for various target groups representing various types of HEI. It is very common in most HEI marketing communication literature to recommend the one best tool and yet emphasis the needs for using multiple tools simultaneously. This concept of combining several marketing communication tools is known as integrated marketing communication (IMC). There are three models under IMC namely, Process Model, RABOSTIC Planning Model and Mix Model (Pickton \& Broderic, 2005). The Process Model focus on how IMC works from sender to receivers, the RABOSTIC Planning Model discuss on how IMC are planned, organized and managed and the Mix Model is on what mix is appropriate.

The conceptual framework: The classifications on source of information as discussed under relationship marketing were reintroduced by Hughes and Fill (2007) as the macro-framework of marketing communications. Adopting the macro-framework, this paper is build based on the conceptual framework as displayed in figure 1. It starts with the receiver which is the successful applicant who is now registered at reputable HEI. They had gone through the process of searching for information though planned and unplanned messages send via various marketing communication tools. 
Figure 1: The conceptual framework

\begin{tabular}{|c|c|c|c|c|c|c|}
\hline \multicolumn{7}{|l|}{$\mathbf{M}$} \\
\hline \multicolumn{7}{|c|}{ Source of Information } \\
\hline \multirow[t]{9}{*}{$\mathbf{m}$} & \multirow{2}{*}{$\begin{array}{l}\text { Relationship } \\
\text { Marketing } \\
\text { m }\end{array}$} & \multicolumn{2}{|c|}{ Marketing Communication Tools } & \multirow[t]{9}{*}{$\mathbf{m}$} & \multirow{9}{*}{ 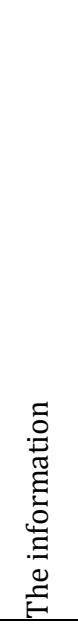 } & \multirow{9}{*}{ 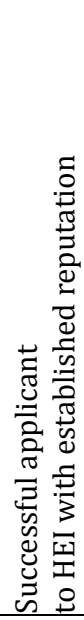 } \\
\hline & & Category & Medium & & & \\
\hline & \multirow[t]{4}{*}{ Planned } & Advertisement & $\begin{array}{l}\text { Newspapers } \\
\text { Magazines } \\
\end{array}$ & & & \\
\hline & & Personal Selling & University visits & & & \\
\hline & & Direct Selling & Education fair & & & \\
\hline & & $\begin{array}{l}\text { Public } \\
\text { Relationship }\end{array}$ & $\begin{array}{l}\text { Prospectus } \\
\text { University web site } \\
\text { League tables }\end{array}$ & & & \\
\hline & \multirow[t]{2}{*}{ Unplanned } & Word-Of-Mouth & $\begin{array}{l}\text { Parents } \\
\text { Relatives/spouse } \\
\text { Friends }\end{array}$ & & & \\
\hline & & Referrals & Careers advisor & & & \\
\hline & & & & & & \\
\hline
\end{tabular}

\section{Methodology}

The study utilized descriptive statistics and exploratory factor analysis on a set of primary data to answer the objective of the study. This section describes the data collection method, defines variable of interest and introduces the statistical methods used in the analysis. The description of the sample in the primary data is also included.

Data collection: Self administrated survey was conducted among first year students registered at University of Malaya in March 2014. Adopting the instrument modified from Nagaraj et al. (2008), 677 students from various faculties were asked whether they had referred to any source of information in the process of selecting HEI. The listed sources in the questionnaire were (1)prospectus, (2)university web site, (3)education fair, (4)university visits, (5)league tables, (6)newspapers, (7)magazines, (8)parents, (9)relatives/spouse, (10)friends and (11)career advisors. They were also allowed to write other sources, if any, in a space provided. In order to get how much they valued each sources, respondent was also required to identify which source as their most important resources being referred. Social-demographic information such as age, gender, ethnicity, nationality, entrance qualification used and field of study were also included in the questionnaire. All data management and analysis were conducted with IBM SPSS 22.0. After data cleaning, 12 respondents were excluded for analysis resulting with final sample of 665 .

Data analysis: The study utilized descriptive analysis. In specific, frequency and percentage is generated for all source of information being referred and selected as the most important source. For the number of sources being referred, the descriptive statistics namely arithmetic mean, median, quartiles, minimum and maximum is computed. In assessing how important each sources in providing information from the respondents' point of view, two percentages were calculated. First, the percentage is calculated base as proportion of respondents selecting the specific source of information as the most important source with respect to the number of total respondent. The second percentage is similar with the first ones except the denominator is now the number of total respondent who claim to be referring to the source is generated. Both percentages lead to different interpretation and conclusion. Two-stage clustering technique was used to identify which other source had being referred with reference to the source they had selected as the most importance one. In the analysis, given that a source was considered as the most important source of information, their response on whether they had also referred to the other sources becomes the input variables in the analysis. The clustering process will give each input variables a score known as important prediction score as indicator on which input is the best indicator to differentiate each generated cluster. The score ranged between 0 and 1 . High score indicate that the input variable is significant in discriminating the clusters. Cross-tabulation between the important sources and other referred source is also generated to support the result. 
The Sample: The sample represents respondents aged between 18 to 26 years old who are currently enrolled as a first year students from various undergraduate program at The University of Malaya. Out of 668 respondents, $97 \%$ of them were between 20 and 21 years old. They were either fresh high school leavers, had attended a pre-University program or A-Level; or had completed a diploma program offered by private or public Higher Education Intuition (HEI). More than $60 \%$ of the respondents are female student. The unbalance in gender is reflecting the current trend in enrollment at HEI in the country. The sample is dominated by Chinese. Based on their field of study, $62 \%$ are social science students and the rest are science based. The distribution of the students in the sample by field of study in details is shown in Table 1.

Table 1: Social-demographic characteristics of sample

\begin{tabular}{|c|c|c|c|c|c|}
\hline Characteristic & Frequency & $\%$ & Characteristic & Frequency & $\%$ \\
\hline Age & & & Highest Education Attainment & & \\
\hline Nineteen and younger & 6 & $0.9 \%$ & High school & 445 & $66.9 \%$ \\
\hline Twenty & 206 & $31.0 \%$ & certificate/diploma & & \\
\hline Twenty one & 437 & $65.7 \%$ & Foundation Certificate & 210 & $31.6 \%$ \\
\hline Twenty two & 10 & $1.5 \%$ & /A-Level & & \\
\hline Twenty three & 4 & $0.6 \%$ & HEI diploma & 10 & $1.5 \%$ \\
\hline Twenty four and older & 2 & $0.3 \%$ & Field of Study^ ${ }^{\wedge}$ & & \\
\hline Gender & & & Science & & \\
\hline Male & 258 & $38.8 \%$ & & 107 & $16.1 \%$ \\
\hline Female & 407 & $61.2 \%$ & Engineering, manufacturing \& & & \\
\hline Ethnicity & & & construction & & \\
\hline Malay* & 182 & $27.4 \%$ & Agriculture & 25 & $3.8 \%$ \\
\hline Chinese & 415 & $62.4 \%$ & Health & 4 & $0.6 \%$ \\
\hline Indian & 48 & $7.2 \%$ & Others & 119 & $17.9 \%$ \\
\hline Others & 3 & $0.5 \%$ & Non-Science & & \\
\hline \multirow[t]{3}{*}{ Non-Malaysian } & 17 & $2.6 \%$ & Education & 25 & $3.8 \%$ \\
\hline & & & Humanities \& arts & 146 & $22.0 \%$ \\
\hline & & & $\begin{array}{c}\text { Social sciences, business \& } \\
\text { law }\end{array}$ & 239 & $35.9 \%$ \\
\hline
\end{tabular}

Source: From the survey data

Percentage computed based on 665 respondents.

*Including indigenous people and other ethnic group classified as Bumiputera by Department of Statistics, Malaysia.

${ }^{\wedge}$ based on International Standard Classification of Education (UNESCO, 2011)

\section{Results and Discussion}

Sources referred: The most referred source is university web site, parents, friends, education fair and league tables. As shown in Table 2, the three least referred sources were university visits, magazines and newspapers. A part from the 11 listed sources, 10 respondents added that they had referred to other online sources such as social network web pages and blogs, television and radio. The low number of respondents referring to other online sources television and radio could be due to its exclusion as one of sources listed in the questionnaire. This suggests that students were referring to various medium of marketing communication tools. The most popular tools are public relationship, word-of-mouth and public relationship. The observation has similarity with Chung (2010) but contradicting with Bamfo and Atara (2013), Gray et al. (2003) and Messah and Immaculate (2011). This could be due to the facts that their studies had been using sample presenting other focus groups. Further analysis discovered that they did not only refer to only one source for information. The number of sources being referred varied from one to 11 types of sources. $99 \%$ of the respondent in the sample had referred to at least two sources. On average they had looked at least 6 different sources of information. This indicates that students had referred to multiple sources. Hence support the IMC mixed model framework.

Perceived value of the source: Based on the total sample, university website had the most votes as the most important source of information in their decision making followed by education fair, career advisor, league 
table, prospectus, and parents. The percentage of respondent selecting friends, university visits, newspapers, relatives/ spouse and magazines including other online resources as most important source of information were lower as compared with the other six sources. Since none of the respondents select television or radio and only two respondents select other online resources as their most important source of information, its statistics is not shown in Table 2. This shows that even though certain tools are popular, it may not have much value to the students. For example two mediums, parents and friends, were discovered as the second and third highest source being referred but their rank falls into the sixth and seventh position in its importance. To assess which sources plays an important role in providing information to the student, the percentage $\left(\mathrm{W}_{1}\right)$ is not a good indicator because not all respondent had referred to all sources listed. Hence the second percentages as defined in the methodology as $\mathrm{W}_{2}$ were computed and displayed in Figure 2. Box plots on statistics on number of sources referred given that the respective source was the most important source is also shown in the same figure. Each of the box plots shows the minimum, first quartile, median, third quartile and maximum amount of sources referred.

Table 2: Source of information referred, its importance and total number of sources being referred

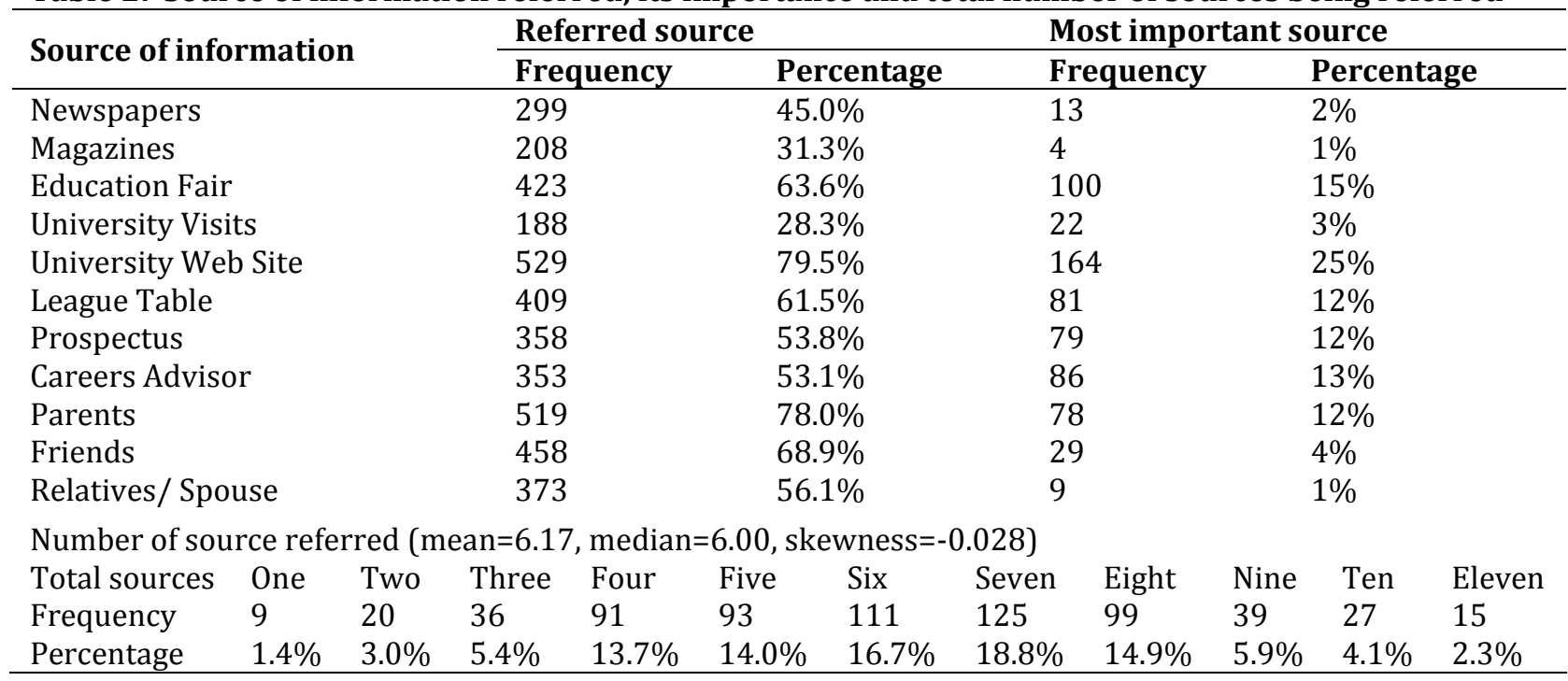

Source: From the survey data. Note: Percentage is computed based on 665 respondents.

Figure 2: The perceived source of information, descriptive statistics on number of sources referred

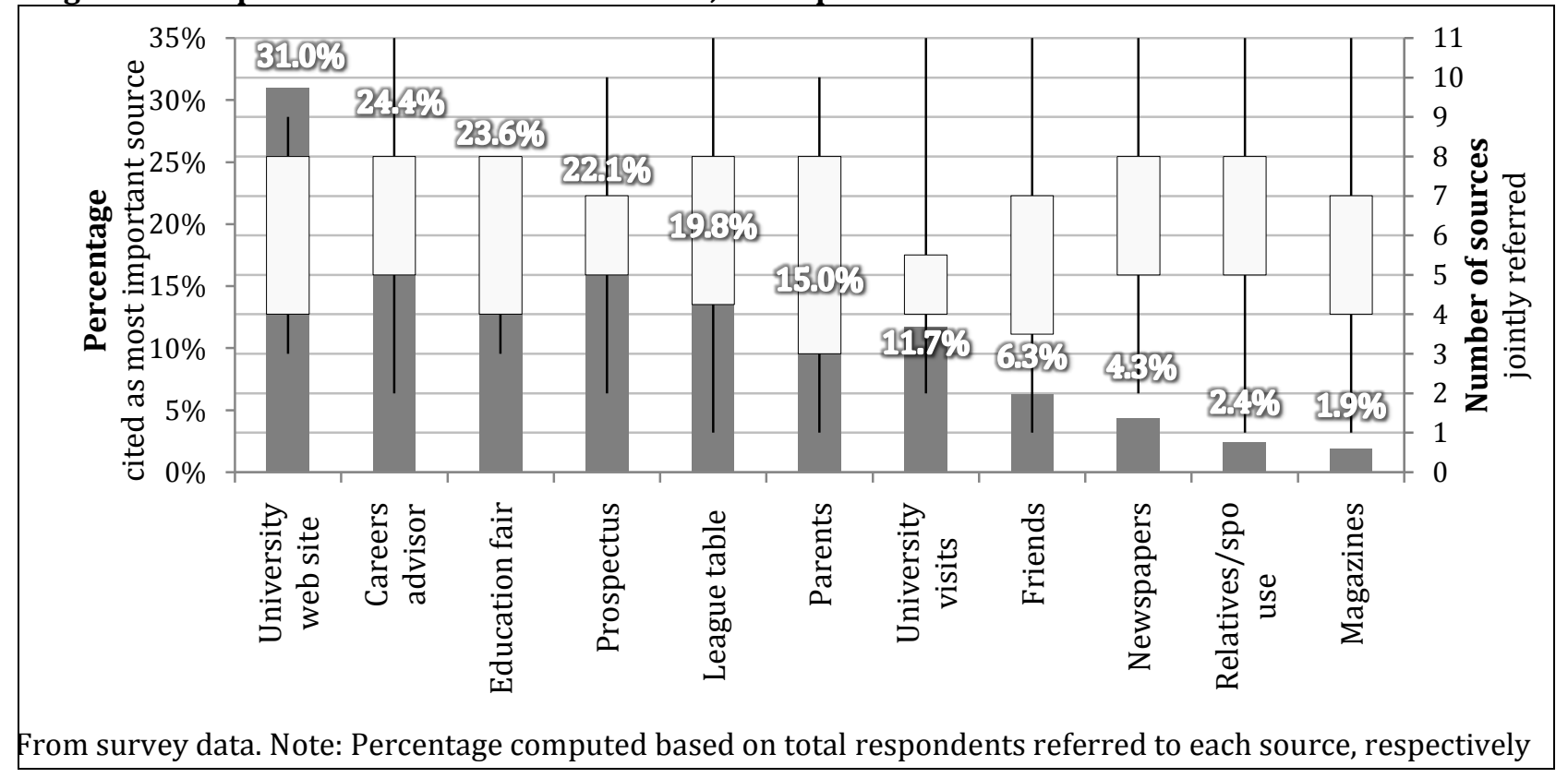


Out of 529 respondents who had browsing the university website, 164 respondents or $31 \%$ of them said the website was their most important source of information. The percentage is also high for those who rated career advisors, education fair, prospectus, league table and parents as their most important source. As shown in Figure 2, the percentages lie between 24\% and 15\%. The value is less than $5 \%$ for newspaper, relative/spouse and magazines. Out of 458 respondent who had referred to their friends, 29 (6\%) of them said that their friends as the most important source of information. However, none of them relies solely on their friends as the only source. Two-third of them had a least referred to three other sources. Depending on which sources the respondent perceived as the most important source, the number of other sources being referred together with the most important source varies. However, as observed in Figure 2, at least two-third of the sub sample had referred to three to five other sources, respectively. Out of 11 listed sources, the only sources with respondent claiming to not refer to other sources are those who refer to league table, parents, friend, relative/spouse and magazine. Nonetheless, this group of respondent is only representing $1.4 \%$ of the total sample. Relative/spouse, newspaper and magazine had been acknowledged by a small group of student to play an important role in transmitting information. At the same time, the data shows that these students still acquired information from other sources. Again, the findings support the IMC mixed model framework. Multiple communication tools medium should be used to ensure the information delivered successfully.

IMC strategy: As concluded in the earlier stage of analysis, marketing strategy planning for HEI should be a mixture of several marketing communication tools. As outlined under IMC Mix Model framework, the appropriate combination of tools and medium of communication should be identified. Results from two-way cluster analysis suggest various behavior patterns. Table 3 shows the clustering result for six sources and the percentage of respondents who had referred to other sources in each cluster. The analysis was not done for the other five sources due to low sample size. The analysis suggests each of the important sources to have two to six cluster groups, each showing different sets of combination of other sources were being referred. Most of the groups have small sample size. It is observed that those who considered:

- University website as the most important source of information is grouped into five groups. Three sources with high important predictor score are prospectus, relative/spouse and friends. Based on crosstabulation results, it is observed that the first cluster represents a group of students who had referred to university website, prospectus, relative/spouse and friends. Students in the second cluster, C2u, had referred to university website but none referred to prospectus and only few referred to relative/spouse and friends. In contrast, the other two clusters had at less than $20 \%$ referred to prospectus but $100 \%$ of them referred to relative/spouse with almost equal percentages referred to friends. Students in C3u had the lowest percentage referring to relative/spouse spouse and friends. In comparison with $\mathrm{C} 4 \mathrm{u}$ and $\mathrm{C} 5 \mathrm{u}$, its percentage on prospectus is high.

- Careers advisor as an important source of information is divided into two groups. The analysis identified newspapers and magazines as the two most important predictors. The first group had relies much on the two medium. The other group of students less relying on both of it.

- Education fair as an important source of information is divided into four groups. The important predictors are prospectus and friends. All students from C4c had referred to education fair, prospectus and friends. $100 \%$ of students in first group had referred to friends and $54 \%$ had referred to prospectus. None in the second group had referred to prospectus, which contradicts with C4c. For the third group, only $61 \%$ and $14 \%$ had referred to both medium, respectively.

- Prospectus as an important source of information is also divided into four groups. There are four important predictors namely, newspaper, magazine, friends and careers advisor. None of the groups had respondent who had referred to all five source. In the first group, the students all referred to prospectus, newspaper, magazine and friends with $73 \%$ referred to careers advisor. None from C2pr and C4pr referred to magazine and small percentage referred to newspaper. The difference in the two clusters is C2pr had higher percentage for friends and careers advisor. C4pr also do not have anybody referred to careers advisor.

- League table as an important source of information is divided into six groups. The five important predictors are newspaper, magazine, education fair, prospectus and friends. The only cluster with $100 \%$ of the respondents referred to newspaper and prospectuses, which are two predators with score equal to 1 , is C2l. Similar with C3l and C6l, students from these clusters had referred to friends and did not referred to magazine. 
Table 3: Output from two-way cluster analysis and cross-tabulation

\begin{tabular}{|c|c|c|c|c|c|c|c|c|c|c|c|c|c|}
\hline \multirow{4}{*}{$\begin{array}{l}\text { Important } \\
\text { source }\end{array}$} & \multirow{3}{*}{\multicolumn{2}{|c|}{ Cluster }} & \multicolumn{11}{|c|}{ Other referred sources } \\
\hline & & & & & \multirow{3}{*}{$\begin{array}{l}\begin{array}{l}\text { Personal } \\
\text { Selling }\end{array} \\
\text { Universit } \\
\text { y visits }\end{array}$} & \multirow{3}{*}{$\begin{array}{l}\begin{array}{l}\text { Direct } \\
\text { Selling }\end{array} \\
\begin{array}{l}\text { Educati } \\
\text { on fair }\end{array}\end{array}$} & \multirow{2}{*}{\multicolumn{3}{|c|}{ Public Relationship }} & \multicolumn{3}{|c|}{ Word-Of-Mouth } & \multirow{3}{*}{$\begin{array}{l}\text { Referral } \\
\text { s } \\
\\
\text { Careers } \\
\text { advisor }\end{array}$} \\
\hline & & & \multicolumn{2}{|c|}{ Advertisement } & & & & & & & & & \\
\hline & $\begin{array}{l}\text { Gr } \\
\text { ou } \\
\text { p }\end{array}$ & $\begin{array}{l}\text { Siz } \\
\text { e }\end{array}$ & $\begin{array}{l}\text { Newsp } \\
\text { apers }\end{array}$ & $\begin{array}{l}\text { Maga } \\
\text { zines }\end{array}$ & & & $\begin{array}{l}\text { Prosp } \\
\text { ectus }\end{array}$ & $\begin{array}{l}\text { University } \\
\text { web site }\end{array}$ & $\begin{array}{l}\text { League } \\
\text { table }\end{array}$ & $\begin{array}{l}\text { Par } \\
\text { ents }\end{array}$ & $\begin{array}{l}\text { Relatives } \\
\text { /spouse }\end{array}$ & $\begin{array}{l}\text { Frie } \\
\text { nds }\end{array}$ & \\
\hline \multirow[t]{6}{*}{$\begin{array}{l}\text { University } \\
\text { web site }\end{array}$} & $\begin{array}{l}\mathrm{C} 1 \\
\mathrm{u}\end{array}$ & 19 & $58 \%$ & $47 \%$ & $68 \%$ & $63 \%$ & $100 \%$ & NA & $53 \%$ & $95 \%$ & $95 \%$ & $\begin{array}{l}100 \\
\%\end{array}$ & $47 \%$ \\
\hline & $\begin{array}{l}\mathrm{C} 2 \\
\mathrm{u}\end{array}$ & 13 & $54 \%$ & $23 \%$ & $31 \%$ & $62 \%$ & $0 \%$ & & $0 \%$ & $85 \%$ & $31 \%$ & $69 \%$ & $23 \%$ \\
\hline & $\begin{array}{l}\mathrm{C} 3 \\
\mathrm{u}\end{array}$ & 16 & $25 \%$ & $25 \%$ & $6 \%$ & $69 \%$ & $75 \%$ & & $56 \%$ & $\begin{array}{l}100 \\
\%\end{array}$ & $6 \%$ & $13 \%$ & $56 \%$ \\
\hline & $\begin{array}{l}\mathrm{C} 4 \\
\mathrm{u}\end{array}$ & 19 & $32 \%$ & $21 \%$ & $5 \%$ & $84 \%$ & $11 \%$ & & $58 \%$ & $95 \%$ & $100 \%$ & $89 \%$ & $84 \%$ \\
\hline & C5 & 11 & $0 \%$ & $0 \%$ & $9 \%$ & $0 \%$ & $18 \%$ & & $36 \%$ & 100 & $100 \%$ & $91 \%$ & $0 \%$ \\
\hline & $\mathrm{u}$ & & & & & & $* *$ & & & $\%$ & $* * *$ & $*$ & \\
\hline \multirow{2}{*}{$\begin{array}{l}\text { Careers } \\
\text { advisor }\end{array}$} & C1c & 62 & $31 \%$ & $13 \%$ & $29 \%$ & $65 \%$ & $35 \%$ & $68 \%$ & $52 \%$ & $76 \%$ & $47 \%$ & $68 \%$ & NA \\
\hline & $\mathrm{C} 2 \mathrm{c}$ & 24 & $\begin{array}{l}100 \% \\
* *\end{array}$ & $\begin{array}{l}96 \% \\
* * *\end{array}$ & $58 \%$ & $79 \%$ & $58 \%$ & $100 \%$ & $71 \%$ & $\begin{array}{l}100 \\
\%\end{array}$ & $79 \%$ & $92 \%$ & \\
\hline \multirow[t]{4}{*}{$\begin{array}{l}\text { Education } \\
\text { fair }\end{array}$} & $\mathrm{C} 1 \mathrm{e}$ & $\begin{array}{l}2 \\
4\end{array}$ & $83 \%$ & $75 \%$ & $38 \%$ & NA & $54 \%$ & $96 \%$ & $58 \%$ & $96 \%$ & $92 \%$ & $\begin{array}{l}100 \\
\%\end{array}$ & $75 \%$ \\
\hline & $\mathrm{C} 2 \mathrm{e}$ & $\begin{array}{l}2 \\
3\end{array}$ & $0 \%$ & $9 \%$ & $13 \%$ & & $0 \%$ & $61 \%$ & $43 \%$ & $74 \%$ & $74 \%$ & $96 \%$ & $43 \%$ \\
\hline & C3e & $\begin{array}{l}2 \\
8\end{array}$ & $54 \%$ & $46 \%$ & $18 \%$ & & $61 \%$ & $82 \%$ & $54 \%$ & $64 \%$ & $21 \%$ & $14 \%$ & $54 \%$ \\
\hline & $\mathrm{C} 4 \mathrm{e}$ & $\begin{array}{l}2 \\
5\end{array}$ & $36 \%$ & $8 \%$ & $24 \%$ & & $\begin{array}{l}100 \% \\
*\end{array}$ & $64 \%$ & $84 \%$ & $\begin{array}{l}100 \\
\%\end{array}$ & $52 \%$ & $\begin{array}{l}100 \\
\% \\
* * *\end{array}$ & $52 \%$ \\
\hline \multirow[t]{5}{*}{ Prospectus } & C1pr & $\begin{array}{l}1 \\
1\end{array}$ & $100 \%$ & $100 \%$ & $55 \%$ & $82 \%$ & $\mathrm{NA}$ & $55 \%$ & $73 \%$ & $\begin{array}{l}100 \\
\%\end{array}$ & $91 \%$ & $\begin{array}{l}100 \\
\%\end{array}$ & $73 \%$ \\
\hline & $\mathrm{C} 2 \mathrm{pr}$ & $\begin{array}{l}1 \\
3\end{array}$ & $38 \%$ & $0 \%$ & $8 \%$ & $92 \%$ & & $100 \%$ & $100 \%$ & $77 \%$ & $92 \%$ & $92 \%$ & $92 \%$ \\
\hline & C3pr & $\begin{array}{l}3 \\
7\end{array}$ & $54 \%$ & $46 \%$ & $19 \%$ & $65 \%$ & & $78 \%$ & $76 \%$ & $49 \%$ & $38 \%$ & $32 \%$ & $51 \%$ \\
\hline & $\mathrm{C} 4 \mathrm{pr}$ & $\begin{array}{l}1 \\
7\end{array}$ & $6 \%$ & $0 \%$ & $35 \%$ & $35 \%$ & & $82 \%$ & $47 \%$ & $94 \%$ & $41 \%$ & $71 \%$ & $0 \%$ \\
\hline & & & $*$ & $* * *$ & & & & & & & & $*$ & $* *$ \\
\hline \multirow[t]{7}{*}{$\begin{array}{l}\text { League } \\
\text { table }\end{array}$} & C1l & $\begin{array}{l}1 \\
8\end{array}$ & $50 \%$ & $72 \%$ & $50 \%$ & $100 \%$ & $94 \%$ & $83 \%$ & NA & $78 \%$ & $39 \%$ & $44 \%$ & $56 \%$ \\
\hline & $\mathrm{C} 2 \mathrm{l}$ & $\begin{array}{l}1 \\
2\end{array}$ & $100 \%$ & $0 \%$ & $0 \%$ & $50 \%$ & $100 \%$ & $25 \%$ & & $92 \%$ & $92 \%$ & $\begin{array}{l}100 \\
\%\end{array}$ & $83 \%$ \\
\hline & C3l & $\begin{array}{l}2 \\
3\end{array}$ & $9 \%$ & $0 \%$ & $13 \%$ & $35 \%$ & $43 \%$ & $70 \%$ & & $87 \%$ & $57 \%$ & $\begin{array}{l}100 \\
\%\end{array}$ & $35 \%$ \\
\hline & C4l & 7 & $100 \%$ & $100 \%$ & $0 \%$ & $0 \%$ & $43 \%$ & $43 \%$ & & $86 \%$ & $71 \%$ & $57 \%$ & $100 \%$ \\
\hline & C5l & 9 & $33 \%$ & $22 \%$ & $33 \%$ & $0 \%$ & $0 \%$ & $67 \%$ & & $0 \%$ & $67 \%$ & $67 \%$ & $67 \%$ \\
\hline & C6l & $\begin{array}{l}1 \\
2\end{array}$ & $25 \%$ & $0 \%$ & $33 \%$ & $8 \%$ & $75 \%$ & $100 \%$ & & $67 \%$ & $8 \%$ & $0 \%$ & $8 \%$ \\
\hline & & & * & $* * *$ & & ** & * & & & & & $* *$ & \\
\hline \multirow[t]{5}{*}{ Parents } & C1pa & $\begin{array}{l}2 \\
2\end{array}$ & $27 \%$ & $23 \%$ & $23 \%$ & $59 \%$ & $55 \%$ & $86 \%$ & $41 \%$ & $\mathrm{NA}$ & $0 \%$ & $32 \%$ & $59 \%$ \\
\hline & C2pa & $\begin{array}{l}1 \\
2\end{array}$ & $75 \%$ & $25 \%$ & $0 \%$ & $92 \%$ & $0 \%$ & $42 \%$ & $0 \%$ & & $83 \%$ & $75 \%$ & $58 \%$ \\
\hline & C3pa & $\begin{array}{l}2 \\
6\end{array}$ & $50 \%$ & $42 \%$ & $42 \%$ & $77 \%$ & $62 \%$ & $100 \%$ & $69 \%$ & & $100 \%$ & $96 \%$ & $65 \%$ \\
\hline & C4pa & $\begin{array}{l}1 \\
8\end{array}$ & $0 \%$ & $6 \%$ & $22 \%$ & $17 \%$ & $39 \%$ & $50 \%$ & $39 \%$ & & $94 \%$ & $89 \%$ & $0 \%$ \\
\hline & & & & & * & & * & & * & & $* * *$ & & * \\
\hline
\end{tabular}

Source: From survey data.

Note: $\quad \mathrm{NA}=$ not applicable.

*Important predictor scores $>0.6,{ }^{* *}$ scores $>0.7,{ }^{* * *}$ scores $=1.0$. 
- Parents an important source of information is divided into four groups. University visit, prospectus, league table, relative/spouse and careers advisor are the important predictors. None of the students in any cluster had referred to all five sources and parents. Only all students in C3pa had referred to both parents and relative/spouse. None of the students in C2pa had referred to both parents and university visit; both parents and prospectus; and both parents and league table. To this group of students, they relies parents plus relative/spouse and careers advisor. However, students from C1pa and C4pa, respectively, did not refer to relative/spouse and careers advisor.

The findings from the clustering process reveal the complexity of behavioral patterns in indentifying the best marketing communication tools medium to be combined together. While some tools such as newspapers, magazine, relatives/spouse and friends were not highly valued by the respondent as important source of information, these tools were found to be the other sources being referred together with the source being recognized as the most important source. On the other hand, university visits is the one sources with the reverse effects. The source was only important predictor for parents with lower percentage of students being referring to it given that they had selected parents as the most important source of information.

\section{Conclusion and Recommendation}

Students were referring to various medium of marketing communication tools. The most popular tools are public relationship (university web site), word-of-mouth (parents and friends) and public relationship (league tables). In terms of number, advertisement and personal selling are less referred to for information. Almost everybody referred to at more than one source of information. On average, they had looked at 6 different sources. Only $1.4 \%$ of the total sample admitted to only referring to one sources. Top five most valued sources were university website, career advisors, education fair, prospectus, league table and parents. Even though certain medium are popular, it may not have contributing much information to the students. Depending on which sources the respondent perceived as the most important source, the number of other sources being referred together with the most important source varies with at least at least two-third of the sub-sample had referred to three to five other sources, respectively. It is also noticeable that relative/spouse, newspaper and magazine had been perceived to play an important role in transmitting information among small group of respondent. However, these groups of students had been shown their need to refer many other sources. As proposed by IMC Mixed Model framework, multiple communication tools and medium should be used in HEI marketing to ensure the information is successfully delivered. The various behavior patterns observed in the sample indicates that indentifying the best mix of medium for marketing communication tools is a complex process. As tools such as referrals, public relationships and direct selling were the most valued source of information, the other tools such as advertisement and word-of-mouth did play an important role as supplementary sources of information. While interactive mediums of communication had been rate as more important in delivery information, the tradition mediums were also used as its complementary sources. Nonetheless inference process on the result of the clustering should be done cautiously as the sample size for each cluster is small. The study also is limited by few mediums of communication tools. For future research, traditional tools such as television, radio, banner and pamphlets; other interactive approaches such as personal blogs, mobile apps, social media website and online discussion platform.

\section{References}

Atarah, B. A. \& Peprah, A. A. (2014). Assessing the Influence of Advertising on Student Enrolment in Private Tertiary Institutions in Ghana. International Journal of Business and Social Research, 4(3), 55-65

Bamfo, A. B. \& Atara, B. A. (2013). The role of marketing communications in student enrolment in private universities in Ghana. Global Advanced Research Journal of Management and Business Studies, 2(5), 268-278.

Barnlund, D. C. (2008). A transactional model of communication. In. C. D. Mortensen (Eds.), Communication theory (2nd ed., pp47-57). New Brunswick, New Jersey: Transaction.

Berlo, D. K. (1960). The process of communication. New York, New York: Holt, Rinehart, \& Winston. 
Calonius, H. (1989). Market communication in service marketing", Marketing Thought and Practice in the 1990s. Avlonitis, G.J., Papavasiliou, N.K. and Kouremeos, A.G. (Eds). Proceedings from the XVIIIth Annual Conference of the European Marketing Academy, Athens.

Cant, M. C. \& van Heerden, C. H. (2005). Personal Selling. Juta Academic. Lansdowne Stone and Jacob, 2007

Chung, K. C. (2010). Effective Brand Positioning of Universities in the Ethnic Chinese Community: A New Zealand Perspective. E-Leader Singapore: 1-10.

Duncan, T. \& Moriarty, S. (1997). Driving Brand Value. McGraw-Hill, New York, NY.

Fill, C. \& Jamieson, B. (2006). Marketing communication. Edinburg: United Kingdom

Fill, G. (2009). Marketing Communication: interactivity, communities and content. Harlow: Prentice Hall. ISBN 9780273717225.

Gönroos, C. (2004). The relationship marketing process: communication, interaction, dialogue, value. Journal of Business and Industrial Marketing, 19(2), 99-113.

Gray, B. J., Kim, S. F. \& Llanes, V. A. (2003). Branding universities in Asian markets. Journal of Product \& Brand Management, 12(2), $108-120$.

Hemsley-Brown J. V. \& Oplatka, I. (2006). Universities in a competitive global marketplace: a systematic review of the literature on higher education marketing. International Journal of Public Sector Management, 19(4), 316-338.

Hughes, G. \& Fill, C. (2007). Redefining the nature and format of the marketing communications mix. The Marketing Review, 7(1), 45-57.

Jansen, I. \& Brenn-White, M. (2011). Overview of Current Marketing Initiatives by Higher Education Institutions (HEI) and National Agencies within the European Higher Education Area (EHEA), Report prepared for IPN meeting in Brussels.

Kazmi, S. H. \& Batra, S. K. (2008). Advertising and Sales Promotion (3rd edition). Excel Books. New Delhi ISBN 978-81-7446-639-6

Kotler, P., Adam, S., Brown, L. \& Armstrong, G. (2006). Principles of Marketing, 3rd edn, NSW, Prentice Hall.

Kotler, P., Armstrong, G., Saunders, J. \& Wong, V. (1996). Principal of Marketing. Prentice Hall, New Jersey.

Masterman, G. (2007) Sponsorship: For a Return on Investment. Oxford: Butterworth-Heinemann

McDonald, C. (1991). Sponsorship and the Image of the Sponsor. European Journal of Marketing, 25(11), 31 38

Messah, O. B. \& Immaculate, M. J. N. (2011). Effect of Selected Marketing Communication Tools on Student Enrolment in Private Universities in Kenya. European Journal of Business and Management, 3(3), 172-205.

Nagaraj, S., Munisamy, S., Mohd Jaafar, N. I., Abdul Wahab, D. \& Mirzaei, T. (2008). How Do Undergraduates Choose Their University? A Study of First Year University of Malaya Students. FEA Working Paper Series 2008-8, Kuala Lumpur: Faculty of Economics and Administration, University of Malaya.

Pickton, D. \& Broderick, A. (2005). Integrated Marketing Communications. FT Prentice Hall. Essex: UK.

Schramm, W. (1954). How communication works. In W. Schramm (Ed.), The process and effects of communication. Urbana, Illinois: University of Illinois Press.

Shannon, C. E. \& Weaver, W. (1949). The mathematical theory of communication. Urbana: University of Illinois Press.

United Nations Education, Scientific and Cultural Organization (UNESCO). (2012). International Standard Classification of Education 2011. UNESCO Institute of Statistics. ISBN 978-92-9189-123-8. Retrieved from http://www.uis.unesco.org/Education/Documents/isced-2011-en.pdf

Wood, J. T. (2009). Communication in our lives (4th ed.). Belmont, CA: Thomson-Wadsworth. 